\title{
PROTEÍNAS DE FASE AGUDA EM CÃES E GATOS
}

Ivan Felismino Charas dos Santos ${ }^{1}$ Deise Silva Alberto ${ }^{2}$

SANTOS, I. F. C. dos; ALBERTO, D. S. Proteínas de fase aguda em cães e gatos. Arq. Ciênc. Vet. Zool. UNIPAR, Umuarama, v. 17, n. 1, p. 55-62, jan./mar. 2014.

RESUMO: As proteínas de fase aguda (PFA) são um grupo de proteínas sanguíneas que apresentam alterações nas suas concentrações em animais acometidos por infecções, inflamações, trauma cirúrgico ou mesmo submetido ao estresse. São proteínas que alteram as suas concentrações em pelo menos $25 \%$ durante a inflamação. As PFA consistem em proteínas de fase aguda negativa e/ou positiva, diminuindo ou aumentando a sua concentração, respectivamente, em resposta a um estímulo inflamatório. Dentre as PFA negativas mais importantes estão a albumina e a transferina. As PFA positivas são a haptoglobina (Hp), proteína C-reativa (CRP), amiloide A-sérico (SAA), ceruloplasmina (Cp), fibrinogênio e a alfa 1 glicoproteina ácida(APG). As avaliações da concentração das PFA e proteínas totais propiciam subsídios para adequada interpretação do estado de hidratação, bem como de inflamação, infecção, doença imunomediada e alteração da síntese proteica. Sendo as PFA mediadores inflamatórios das respostas imunes agudas, e consideradas marcadoras das lesões teciduais na sua fase aguda nos animais, é importante realizar uma revisão sobre as PFA mais importantes e suas funções nos cães e gatos.

PALAVRAS-CHAVE: Dor. Estresse. Inflamação. Pequenos animais. Resposta inflamatória aguda.

\section{ACUTE-PHASE PROTEINS IN DOGS AND CATS}

ABSTRACT: Acute-phase proteins (APP) are a group of blood proteins exhibiting changes in their concentrations in animals suffering from infections, inflammation, surgical trauma or even which have been subjected to stress. These proteins present at least $25 \%$ changes in their concentrations during inflammation. APPs consist of negative- and positive-phase proteins that can decrease or increase their concentration in response to an inflammatory stimulus. The most important negative APP are albumin and transferrin; and the most important positive APP are haptoglobin (Hp), C-reactive protein (CRP), serum amyloid A (SAA), ceruloplasmin (Cp), fibrinogen and alpha 1 glycoprotein acid (AGP). APP concentration and total protein reviews provide information for proper interpretation of hydration status, as well as inflammation, infection, immune-mediated diseases and impaired protein synthesis. APPs are inflammatory mediators of acute immune responses and are considered markers for tissue damages in the acute phase in animals. Therefore, it is important to further review the most important APPs and their functions in dogs and cats.

KEYWORDS: Pain. Stress. Inflammation. Small animals. Acute inflammation response.

\section{PROTEÍNAS DE FASE AGUDA EN PERROS Y GATOS}

RESUMEN: Las proteínas de fase aguda (PFA) son un grupo de proteínas sanguíneas que presentan cambios en sus concentraciones en animales acometidos por infecciones, inflamaciones, trauma quirúrgico o mismo sometido a estrés. Son proteínas que alteran sus concentraciones de al menos $25 \%$ durante la inflamación. Las PFA consisten en proteínas de fase aguda negativa y/o positiva, disminuyendo o aumentando su concentración, respectivamente, en respuesta a un estímulo inflamatorio. Entre las PFA negativas más importantes están la albúmina y la transferrina. Las PFA positivas son la haptoglobina (Hp), proteína $\mathrm{C}$ - reactiva $(\mathrm{CRP})$, amiloideo A-sérico (SAA), ceruloplasmina $(\mathrm{Cp})$, fibrinógeno y la alfa 1-glicoproteína ácida (APG). Las evaluaciones de la concentración de las PFA y proteínas totales proporcionan informaciones para la interpretación apropiada del estado de hidratación, así como de la inflamación, infección, enfermedad inmune-mediada y alteración de síntesis proteica. Siendo las PFA mediadores de respuestas inmunes inflamatorias agudas y consideradas marcadoras de lesiones tisulares en su fase aguda en los animales, es importante llevar a cabo una revisión sobre las PFA más importantes y sus funciones en los perros y gatos.

PALABRAS CLAVE: Dolor. Estrés. Inflamación. Animales pequeños. Respuesta inflamatoria aguda.

\section{Introdução}

As proteínas são substâncias essenciais à vida, representando a base da estrutura de células, tecidos e órgãos. Funcionam como catalisadores enzimáticos nas reações bioquímicas, na manutenção da pressão coloide osmótica e na defesa orgânica sob forma de anticorpos (KANEKO; HARVEY; BRUSS, 2008). É a substância mais abundante no plas- ma, variando entre 6 a $7 \mathrm{~g} / \mathrm{dL}$ comparando com a glucose, 0,1 $\mathrm{g} / \mathrm{dL}$ ou 0,35 g/dL de sódio (ECKERSALL; BELL, 2010).

A resposta sistêmica ao processo inflamatório é uma resposta de fase aguda (RFA) de defesa, sendo complexa e não específica que se inicia imediatamente após qualquer inflamação, infecção, injúria tecidual, trauma cirúrgico, crescimento neoplásico ou alteração imunológica (SERIN; ULUTAS, 2010).

DOI: https://doi.org/10.25110/arqvet.v17i1.2014.4918

${ }^{1}$ Prof. Dr. Assistente de Cirurgia Animal. Faculdade de Veterinária. Universidade Eduardo Mondlane. Moçambique. Pós-Doutorando em Cirurgia Animal. Faculdade de Medicina Veterinária e Zootecnia (FMVZ). Universidade Estadual Paulista (UNESP). Botucatu. Bolsista Fapesp. Email: ivansantos7@ hotmail.com

${ }^{2}$ Médica Veterinária Autônoma. São Paulo. Brasil. 
A RFA consiste em reações locais e sistêmicas, tendo a finalidade de limitar a lesão tecidual, isolar e destruir microrganismos, e ativar o processo de reparação necessário para restaurar o equilíbrio das funções orgânicas (GARCIA; ISSY; SAKATA, 2002). As reações locais envolvem a agregação plaquetária, vasodilatação, acúmulo e ativação de granulócitos e células mononucleares que vão liberar as citocinas (interleucinas) e interferons. Esses mediadores agem em receptores específicos de diferentes células-alvo, provocando uma reação sistêmica (NAKAMURA et al., 1998; GARCIA; ISSY; SAKATA, 2002). As reações sistêmicas incluem a febre, dor, leucocitose, aumento da velocidade de hemossedimentação, aumento da secreção do hormônio adrenocorticotrófico $(\mathrm{ACTH})$, diminuição dos níveis séricos de ferro e zinco, balanço nitrogenado negativo, ativação do complemento e da cascata de coagulação e mudança na concentração de algumas proteínas plasmáticas, as denominadas proteínas da fase aguda (PFA), sintetizadas no fígado (NAKAMURA et al., 1998; GARCIA; ISSY; SAKATA, 2002).

As PFA que diminuem de concentração durante a inflamação são denominadas de PFA negativa - Albumina e Transferrina, enquanto as que aumentam de concentração são denominadas de PFA positivas - Proteína $\mathrm{C}$ reativa (CRP), Amiloide A sérica A (SAA), Haptoglobina (Hp), alfa 1 glicoproteina ácida (APG), Ceruloplasmina (Cp), e fibrinogênio (CÉRON; ECKERSALL; MARTINEZ-SUBIELA, 2005).

A concentração sérica das PFA está estritamente ligada à severidade do processo inflamatório, portanto, utiliza-las como um marcador da inflamação facilita a detecção precoce desse processo, proporcionando uma rápida restauração da homeostase, especialmente em casos em que os sinais clínicos não são observados (GARCIA; ISSY; SAKATA, 2002). As PFA aumentam em resposta a diferentes doenças, a avaliação dessas proteínas é uma importante ferramenta para a precocidade do diagnóstico, prognóstico e monitoramento da doença. Paralelamente, poder-se-á utilizar as PFA como parâmetro para caracterização de um processo inflamatório, comparando com os resultados do leucograma. Tendo em vista que as PFA agem como mediadores inflamatórios das respostas imunes agudas, e são consideradas marcadoras das lesões teciduais na sua fase aguda em pequenos animais, o objetivo do trabalho foi realizar uma revisão sobre as PFA mais importantes e suas funções nos cães e gatos.

\section{Processo inflamatório e a resposta de fase aguda}

A proteína total é composta pelas concentrações da albumina e das globulinas. A albumina é a maior proteína simples encontrada no soro, sintetizada no citoplasma dos hepatócitos e constitui cerca de $35 \%$ a $50 \%$ da proteína total (GARCIA; ISSY; SAKATA, 2002). É uma proteína osmoticamente ativa, responsável por $75 \%$ da atividade osmótica do plasma. Outra importante função é a ligação e transporte de outras substâncias séricas, como a tiroxina e a bilirrubina não conjugada (GARCIA; ISSY; SAKATA, 2002).

As globulinas representam a outra fração das proteínas totais e são divididas em: $\alpha, \beta$ e $\gamma$ globulinas. As $\alpha$ globulinas são a fração que mais rapidamente migram das globulinas e atuam no transporte da tiroxina, lipídios, insulina, cobre e da hemoglobina; e na inibição da tripsina, quimiotripsina, trombina, proteases, etc. As $\beta$ globulinas englo- bam os complementos (C3, C4), hemopexina, transferrina, ferritina e a proteína C-reativa (CÉRON; ECKERSALL; MARTINEZ-SUBIELA, 2005). As $\gamma$ globulinas subdividem em imunoglobulinas e suas frações IgA, IgG, IgM. A fonte das imunoglobulinas são os plasmócitos, diferenciados a partir de linfócitos sensibilizados por estimulação antigênica, fazendo parte do processo imunológico da resposta humoral (CÉRON; ECKERSALL; MARTINEZ-SUBIELA, 2005).

A RFA é um processo dinâmico que envolve mudanças sistêmicas e metabólicas, formando um mecanismo de defesa primário e não específico contra injúrias ao organismo antes do sistema imune (imunidade específica) ser ativado (PETERSEN; NIELSEN; HEEGAARD, 2004). A RFA, considerada parte do sistema imune inato, é o primeiro estágio da reação inflamatória, sendo um processo não específico que ocorre no organismo logo após qualquer injúria tecidual antes de alteração leucocitária. Essa resposta consiste em alterações na concentração das PFA (GABAY; KUSHNER, 2001; CÉRON; ECKERSALL; MARTINEZ-SUBIELA, 2005).

A maioria das PFA positivas são glicoproteínas sintetizadas, principalmente, por hepatócitos sob a estimulação de citocinas pró-inflamatórias liberadas na corrente sanguínea na fase aguda da inflamação (CÉRON; ECKERSALL; MARTINEZ-SUBIELA, 2005).

A concentração máxima das PFA é atingida entre 24 a 48 horas após o início da RFA. A diminuição da concentração ocorre em paralelo à recuperação da injúria. Em geral, um mecanismo de retroalimentação limita essa resposta de acordo com o reestabelecimento da homeostase, levando à resolução do quadro entre quatro a sete dias após o estímulo inicial (PETERSEN; NIELSEN; HEEGAARD, 2004).

O processo inflamatório inicia-se no local do trauma. Os macrófagos e os monócitos estimulam a liberação de citocinas, especialmente a interleucina-1 (IL-1) e o fator de necrose tumoral (FNT), consideradas interleucinas primárias. Essas interleucinas primárias induzem a liberação de mais citocinas, destacando-se a interleucina-6 (IL-6), que tem sido considerada a principal indutora da síntese das PFA pelo fígado e mediadora das respostas de defesa orgânica (GARCIA; ISSY; SAKATA, 2002). Essas citocinas são produzidas por diferentes células, incluindo os monócitos, macrófagos, neutrófilos, linfócitos, fibroblastos, células endoteliais e epiteliais (GABAY; KUSHNER, 2001).

O fígado é o principal local de produção e liberação de PFA, sendo que a IL-6 é a principal citocina indutora na produção de proteína $\mathrm{C}$ reativa (CRP) pelos hepatócitos, principalmente em cães. A IL-1 e o FNT aparentemente não são capazes de induzir a síntese hepática de CRP, isoladas ou combinadas, mas são consideradas as principais moduladoras na RFA (CÉRON; ECKERSALL; MARTINEZ-SUBIELA, 2005). A análise da concentração de citocinas pode ser utilizada para quantificar a resposta sistêmica perante uma infecção ou inflamação (PETERSEN; NIELSEN; HEEGAARD, 2004; CÉRON; ECKERSALL; MARTINEZ-SUBIELA, 2005).

\section{Funções biológicas das proteínas de fase aguda}

O papel fisiológico das PFA não é completamente esclarecido. Aparentemente, as PFA estão envolvidas na re- 
gulação da resposta imune, da inflamação e infecção, e na reparação e recuperação dos tecidos lesados (MURATA; SHIMADA; YOSHIOKA, 2004; CÉRON; ECKERSALL; MARTINEZ-SUBIELA, 2005). Existe um equilíbrio entre as funções das PFA, podendo ter tanto uma função pró-inflamatória, aparecendo como percussoras da inflamação, quanto anti-inflamatória, com funções anti-inflamatórias (CÉRON; ECKERSALL; MARTINEZ-SUBIELA, 2005).

Em cães e gatos, as PFA são diferenciadas pela magnitude de resposta a um estímulo, sendo classificadas como principais aquelas que aumentam de 10 a 100 vezes; intermediárias, que aumentam de 2 a 10 vezes; e negativas aquelas que diminuem. A velocidade e a magnitude de resposta das PFA variam dependendo do tipo do estímulo que os animais são submetidos (CÉRON; ECKERSALL; MARTINEZ-SUBIELA, 2005).

As PFA principais (SAA e APG) em gatos apresentam um limite máximo de aumento inferior aos dos humanos, podendo apresentar um aumento de mais de 1000 vezes (CÉRON; ECKERSALL; MARTINEZ-SUBIELA, 2005). Em cães, as PFA principais (CRP e SAA) tem um aumento mais rápido em relação aos humanos, sendo que as diferenças na magnitude e no tempo de resposta são determinadas entre as PFA principais e intermediárias (CÉRON; ECKERSALL; MARTINEZ-SUBIELA, 2005).

As PFA intermediárias ( $\mathrm{Hp}$, APG e Cp) levam um tempo maior para terem as suas concentrações séricas aumentadas e retornar aos valores normais após um estímulo infeccioso ou inflamatório. Em cães, o aumento na concentração da $\mathrm{Cp}$ é superior e eventualmente mais rápido que em humanos, atingindo até o dobro dos valores normais no quarto dia após a inflamação. As PFA intermediárias que aumentam em menor proporção em relação às PFA principais, em animais saudáveis, estão em maior concentração do que as PFA principais (CÉRON; ECKERSALL; MARTINEZ-SUBIELA, 2005).

\section{Classificação das proteínas de fase aguda}

As proteínas de fase aguda podem ser classificadas de acordo com o tipo de resposta quantitativa frente a um estímulo ou de acordo com a função biológica que desempenham (MARTÍNEZ-SUBIELA et al., 2001).

Quanto à variação da concentração em resposta ao estímulo são classificadas em: PFA positivas, que aumentam a sua concentração perante o estímulo (Hp, SAA, CRP, Cp e fibrinogênio); e em PFA negativas, que diminuem a sua concentração perante o estímulo (albumina e transferina) (MARTÍNEZ-SUBIELA et al., 2001).

De acordo com sua função biológica classificam-se em: PFA que intervém em defesa do organismo, sendo as proteínas responsáveis pelas mudanças fisiológicas na presença de um patógeno (CRP, SAA e fibrinogênio) e componentes do sistema complemento; proteínas inibidoras da serina proteases ou serina endopeptidases (antitripsina alfa1 e antiquimiotripsina alfa-1) que limitam a atividade das enzimas liberadas por células fagocitárias; e em PFA transportadoras que possuem atividade antioxidante $(\mathrm{Cp}, \mathrm{Hp}$ e hemopexina), protegendo os tecidos dos metabolitos do oxigênio que são liberados pelos fagócitos durante a inflamação (MARTÍNEZ-SUBIELA et al., 2001).

\section{Importância clínica}

O recente interesse do uso das PFA na medicina veterinária demonstra a grande variedade de aplicação desse marcador biológico em várias situações patológicas, como lesões da mucosa gástrica, pancreatites, resposta inflamatória sistêmica e sepse, neoplasia mamária, linfoma, anemia hemolítica autoimune, poliartrite imunomediada, hiperadrenocorticismo, atraso na cicatrização de feridas, obesidade, doenças cardíacas, piometra e outras situações (ECKERSALL; BELL, 2010).

As vantagens da análise das PFA em relação ao leucograma estão relacionadas com a maior estabilidade em relação aos componentes celulares do sangue; a menor influência por estímulos fisiológicos passageiros em comparação ao recrutamento de leucócitos marginais e; pela flexibilidade de utilizar material congelado (MARTIÍNEZ-SUBIELA; PARRA; CERÓN, 2004).

As PFA consideradas clássicas, como albumina e fibrinogênio, possuem um baixo valor no diagnóstico e monitoração do processo inflamatório (CÉRON; ECKERSALL; MARTINEZ-SUBIELA, 2005). A sensibilidade e a especificidade da avaliação da proporção albumina/globulina (A/G), não é tão elevada quanto à avaliação das PFA positivas para a detecção de doenças clínicas ou subclínicas (CÉRON; ECKERSALL; MARTINEZ-SUBIELA, 2005). Em cães e gatos, uma diminuição na relação $\mathrm{A} / \mathrm{G}$ revela uma estimativa da RFA durante um processo inflamatório ou infeccioso devido à diminuição da albumina e um aumento da globulina (CÉRON; ECKERSALL; MARTINEZ-SUBIELA, 2005).

É importante reconhecer que a concentração das PFA está aumentada em animais com diferentes doenças; sendo assim, um parâmetro de baixa especificidade na determinação da causa. Portanto, a determinação das PFA não deve ser utilizada como um teste diagnóstico inicial para alguma doença em particular (CÉRON; ECKERSALL; MARTINEZ-SUBIELA, 2005). As PFA apresentam uma alta sensibilidade diante as variadas condições que afetam o estado fisiológico do animal, fornecendo evidências de que o animal é acometido por uma inflamação subclínica ou infecção (CÉRON; ECKERSALL; MARTINEZ-SUBIELA, 2005).

Existe uma relação entre os níveis das PFA e a severidade da doença. A concentração sérica das PFA é maior em casos severos ou complicados ou em animais com sinais clínicos de doença em comparação aos que não apresentam sinais clínicos (CÉRON; ECKERSALL; MARTINEZ-SUBIELA, 2005). Nenhuma correlação foi observada entre os títulos de anticorpos e a concentração das PFA em diferentes doenças infecciosas, sendo que os títulos de anticorpos correspondem a uma resposta mais tardia do sistema imune adquirido (CÉRON; ECKERSALL; MARTINEZ-SUBIELA, 2005).

As PFA podem ser utilizadas no teste de função hepática, uma vez que em casos de cirrose terminal há uma diminuição na produção de PFA. Contudo, níveis aumentados foram observados em vários tipos de hepatites, podendo indicar um prognóstico favorável (MARTIÍNEZ-SUBIELA; PARRA; CERÓN, 2004; CÉRON; ECKERSALL; MARTINEZ-SUBIELA, 2005).

A utilidade na monitoração da concentração das PFA na medicina veterinária tem sido demonstrada em vá- 
rias espécies, e as pesquisas realizadas sobre o assunto tem desenvolvido diferentes métodos de análise e produção de kits comerciais (MARTÍNEZ-SUBIELA et al., 2001). O principal problema para o uso rotineiro das PFA é a escassa comercialização dos kits, sendo que esses possuem baixa especificidade, já que existe uma grande quantidade de processos patológicos que podem produzir variações nos resultados dos exames (MARTÍNEZ-SUBIELA et al., 2001). Contudo, as pesquisas sugerem que no futuro as PFA possam ter uma aplicação prática rotineira importante em diversos campos, como no controle e acompanhamento de tratamentos farmacológicos, detecção de processos subclínicos, controle sanitário de matadouros e/ou a monitoração e avaliação do bem-estar animal (MARTÍNEZ-SUBIELA et al., 2001).

\section{Principais proteínas de fase aguda em cães e gatos}

\section{Proteína C Reativa (CRP)}

A CRP foi descoberta durante a resposta de fase aguda na circulação sanguínea de pacientes diagnosticados com pneumonia pneumocócica, sendo denominada de CRP devido a sua capacidade de se ligar ao polissacarídeo $\mathrm{C}$ da bactéria pneumococo (MARTÍNEZ-SUBIELA et al., 2001; PETERSEN; NIELSEN; HEEGAARD, 2004).

A CRP possui um peso molecular entre 100 a 115 $\mathrm{kDa}$, com cinco subunidades de $20 \mathrm{kDa}$ cada, pertencente a família das pentraxinas (MARTÍNEZ-SUBIELA et al., 2001; PETERSEN; NIELSEN; HEEGAARD, 2004; CÉRON; ECKERSALL; MARTINEZ-SUBIELA, 2005; YUKI et al., 2010).

A CRP é um componente do sistema imune inato que realiza um importante papel na exclusão de agentes infecciosos e células danificadas devido a sua capacidade de se ligar a fosfocolina. A CRP pode ativar a via clássica do sistema complemento quando interage com um dos seus ligantes, sugerindo o início da eliminação de células alvo ou microrganismos causadores de infecção, através da interação da imunidade humoral com a celular (GABAY; KUSHNER, 2001).

A concentração da CRP parece influenciar na atividade inflamatória durante o estado de doença, mesmo sem depender de um estímulo específico, seja ele asséptico, de natureza bacteriana ou viral, mas sim em o quão destrutivo e pró-inflamatório esse estímulo possa ser (KJELGAARD-HANSEN, 2004).

As principais funções biológicas da CRP incluem a ativação do sistema complemento e opsonização bacteriana; modulação de monócitos, macrófagos e produção de citocinas e ligação com a cromatina bacteriana e prevenção da migração tissular de neutrófilos (CROSSLEY et al., 2010; YUKI; ITOH; TAKASE, 2010). Contudo, a CRP parece ter um importante papel na remoção de células em apoptose, necrose ou danificadas, contribuindo para a restauração estrutural e funcional dessas células (KJELGAARD-HANSEN, 2004). Durante os primeiros estágios do processo infeccioso, a concentração sérica da CRP aumenta, sendo evidente antes que ocorra a febre (PETERSEN; NIELSEN; HEEGAARD, 2004).

A CRP é uma das principais PFA em cães, sendo caracterizada por apresentar baixos níveis fisiológicos e um rá- pido e acentuado aumento em casos de um estímulo inflamatório sistêmico, seguido de uma rápida normalização quando o estímulo é cessado (KJELGAARD-HANSEN, 2004).

A habilidade da CRP em reconhecer os patógenos, em um nível molecular, e mediar a eliminação desse patógeno por meio do recrutamento do sistema complemento e fagocitose, faz dessa PFA um importante componente da primeira linha de defesa (KJELGAARD-HANSEN, 2004). A CRP inibe a quimiotaxia e a "explosão respiratória" de neutrófilos (MORTENSEN; ZHONG, 2000), ligando-se diretamente a vários microorganismos e degenerando células e os restos celulares pela ativação do sistema complemento pela via clássica C1q e atua como opsonina (GRUYS et al., 2005).

As propriedades cinéticas da CRP canina durante a RFA são caracterizadas por uma baixa concentração na manutenção da homeostase, seguido de uma fase de rápido aumento após o estímulo inflamatório, atingindo o seu pico por volta de 24 horas, com rápida normalização após o fim do estímulo (KJELGAARD-HANSEN, 2004). A sensibilidade diagnóstica da CRP é facilitada pelas propriedades das PFA principais, com baixas concentrações fisiológicas comparadas a um aumento consistente durante a RFA. Acredita-se que a CRP possui uma alta especificidade diagnóstica, uma vez que só é induzida por uma hipercitocinemia pró-inflamatória. Essas propriedades facilitam a utilização da CRP como um marcador sistêmico de atividade inflamatória na rotina diagnóstica e na monitoração do paciente (CÉRON; ECKERSALL; MARTINEZ-SUBIELA, 2005).

Um aumento na concentração sérica da CRP foi descrito após diferentes procedimentos cirúrgicos em cães. A magnitude desse aumento foi relacionada com a intensidade do trauma cirúrgico, sendo maior quanto maior a lesão tecidual produzida (CÉRON; ECKERSALL; MARTINEZ-SUBIELA, 2005). A determinação da concentração sérica da CRP é de maior utilidade no monitoramento pós-operatório do que na contagem de leucócitos (CÉRON; ECKERSALL; MARTINEZ-SUBIELA, 2005).

Cães com hiperadrenocorticismo (HAC) e outras doenças secundárias, apresentam um aumento nas concentrações de CRP e diminuição nas concentrações de albumina. Entretanto, os níveis de CRP em cães com sepse severa e HAC são significativamente mais baixos em comparação aos cães com septicemia e sem HAC (CALDIN et al., 2009).

As concentrações séricas de CRP parecem não ter valor no diagnóstico ou relação com a malignidade do tumor mamário em cães. Entretanto, cães com carcinoma mamário apresentam altos níveis em comparação aos cães saudáveis, o que sugere um papel inflamatório nesse tipo de tumor (PLANELLAS et al., 2009).

Em cães, as concentrações da CRP também são mais elevadas em casos de linfoma, carcinomas e sarcomas, pancreatite, piometra, babesiose, leishmaniose, pneumonia, anemia hemolítica imunomediada, erliquiose, enterite bacteriana e hemorrágica, endotoxemia por E. coli, parvovirose, leptospirose, infecção por Bordetella bronchiseptica e Trypanosoma brucei (MARTÍNEZ-SUBIELA et al., 2001; CÉRON; ECKERSALL; MARTINEZ-SUBIELA, 2005; ECKERSALL; BELL, 2010). As concentrações elevadas de CRP também foram observadas em cadelas em gestação, coincidindo com o período de implantação embrionária (ECKERSALL; BELL, 2010). 
A diminuição na concentração da CRP está relacionada com a sobrevivência de cães com síndrome da resposta inflamatória sistêmica (SRIS) ou em casos de sepse (SHEAHAN et al., 2010). Não foi observada relação entre a idade e o sexo com a concentração da CRP em cães saudáveis (KJELGAARD-HANSEN, 2004).

Em gatos, a CRP apresenta um aumento pouco significativo ou parece não ter sua concentração alterada em casos de inflamação (CÉRON; ECKERSALL; MARTINEZ-SUBIELA, 2005).

\section{Amiloide A Sérico (SAA)}

O amiloide A sérico (SAA) é uma apolipoproteína capaz de se associar rapidamente com lipoproteínas de alta densidade durante uma inflamação, tendo potencial para influenciar o metabolismo do colesterol durante um processo inflamatório (GABAY; KUSHNER, 2001; MARTÍNEZ-SUBIELA et al., 2001). Na sua forma não conjugada, seu peso molecular é de $180 \mathrm{kDa}$ e após sua desnaturação, o peso estimado de suas subunidades é de 9 a 14 kDa (GABAY; KUSHNER, 2001; MARTÍNEZ-SUBIELA et al., 2001; PETERSEN; NIELSEN; HEEGAARD, 2004).

O SAA foi descrito como indutor da adesão e quimiotaxia de fagócitos e linfócitos, contribuindo para a inflamação descrita nos casos de arteriosclerose em artérias coronárias, devido ao aumento na oxidação de lipoproteínas de baixa densidade (GABAY; KUSHNER, 2001).

É um marcador de inflamação, infecção, e trauma, não específico, produzido pelos hepatócitos (PETERSEN; NIELSEN; HEEGAARD, 2004; SHEAHAN et al., 2010). A sua produção também foi associada a outros órgãos além do fígado, como intestinos, rins, medula óssea, adipócitos, e pela glândula mamária (em casos de mastite) em diferentes espécies animais (CÉRON; ECKERSALL; MARTINEZ-SUBIELA, 2005). Por outro lado, a função biológica dessa PFA ainda não é clara (PETERSEN; NIELSEN; HEEGAARD, 2004).

O SAA é considerado uma das principais PFA em gatos, sendo considerada a proteína que responde mais rápido a um estímulo inflamatório e/ou infeccioso nos gatos (CÉRON; ECKERSALL; MARTINEZ-SUBIELA, 2005). Em diferentes casos de doenças inflamatórias e infecciosas em gatos, foi observado um aumento superior a 55 vezes na concentração de SAA (CÉRON; ECKERSALL; MARTINEZ-SUBIELA, 2005).

Segundo Eckersall e Bell (2010), o SAA está presente durante os estágios iniciais da RFA em gatos, entretanto, estudos mais detalhados são necessários para tornar possível o uso da SAA como um marcador no diagnóstico de inflamação em gatos (KAJIKAWA et al., 1999).

Em gatos, a concentração do SAA aumenta em casos de insuficiência renal e em outras doenças que acometem o trato urinário (CÉRON; ECKERSALL; MARTINEZ-SUBIELA, 2005).

\section{Haptoglobina}

A haptoglobina (Hp) é uma globulina glicoproteica de peso molecular de $81 \mathrm{kDa}$ (SHIM et al., 1971; PETERSEN; NIELSEN; HEEGAARD, 2004; CÉRON; ECKER-
SALL; MARTINEZ-SUBIELA, 2005; SHEAHAN et al., 2010).

Várias funções foram propostas para essa proteína de fase aguda, dentre elas a prevenção da perda de ferro pela formação de complexo estáveis com a hemoglobina $(\mathrm{Hb})$ livre circulante na corrente sanguínea (PETERSEN; NIELSEN; HEEGAARD, 2004). Outras funções incluem a modulação da função de linfócitos e macrófagos, inibição da atividade da catepsina e da quimiotaxia granulocítica e a fagocitose (CÉRON; ECKERSALL; MARTINEZ-SUBIELA, 2005).

Acredita-se que a Hp possui um efeito bacteriostático por restringir a disponibilidade de ferro necessário ao crescimento bacteriano (PETERSEN; NIELSEN; HEEGA$\mathrm{ARD}, 2004)$. A excreção renal de hemoglobina livre não é observada até a saturação de total da $\mathrm{Hp}$ disponível. O complexo $\mathrm{Hp}-\mathrm{Hb}$ é geralmente direcionado ao fígado pelo sistema reticuloendotelial e metabolizado pelas células de Kuppfer (MARTÍNEZ-SUBIELA et al., 2001; PETERSEN; NIELSEN; HEEGAARD, 2004). Além do fígado, a Hp pode ser produzida nos pulmões, tecido adiposo, baço e rins (CÉRON; ECKERSALL; MARTINEZ-SUBIELA, 2005).

Em casos de endocrinopatias observa-se um aumento moderado na concentração da Hp. Em cães com hiperadrenocorticismo, diabetes cetoacidótica, enfermidades do trato respiratório ou urinário, enfermidades pruriginosas da pele e desordens neurológicas, ocorre aumento significativo da Hp (MARTIÍNEZ-SUBIELA; PARRA; CERÓN, 2004). Contudo, a administração de anti-helmínticos induz um aumento nos níveis de Hp no soro (MARTIÍNEZ-SUBIELA; PARRA; CERÓN, 2004).

Em cães, a avaliação dos níveis séricos da Hp pode ser útil quando existem suspeitas de anemia hemolítica, seja ela infecciosa, autoimune ou por causas tóxicas; leishmaniose e trauma cirúrgico, sendo que nesses casos ocorre uma diminuição da concentração da Hp (MARTÍNEZ-SUBIELA et al., 2001; CÉRON; ECKERSALL; MARTINEZ-SUBIELA, 2005; SHEAHAN et al., 2010).

É comprovado que a administração de glicocorticoides em cães, provoca um aumento nas concentrações de Hp, sem afetar os níveis de CRP, SAA e Cp (MARTIÍNEZ-SUBIELA; PARRA; CERÓN, 2004).

\section{Ceruloplasmina}

A ceruloplasmina $(\mathrm{Cp})$ é uma glicoproteína com peso molecular de $151 \mathrm{kDa}$, que transporta parte do cobre (RICE, 1963). Cada molécula transporta de 6 a 8 átomos de cobre variando de acordo com a espécie (MARTÍNEZ-SUBIELA et al., 2001; CÉRON; ECKERSALL; MARTINEZ-SUBIELA, 2005).

$\mathrm{O}$ aumento da concentração de Cp é maior e mais rápido em cães do que em humanos, atingindo valores duas vezes maiores do que o normal após cirurgia ou em presença de diversos processos inflamatórios e infecciosos, como piometras e leishmaniose, enfermidades do trato respiratório ou urinário, enfermidades pruriginosas da pele e desordens neurológicas (MARTÍNEZ-SUBIELA et al., 2001; MARTIÍNEZ-SUBIELA; PARRA; CERÓN, 2004; CÉRON; ECKERSALL; MARTINEZ-SUBIELA, 2005).

Pode atuar como um agente anti-inflamatório por 
reduzir a quantidade de neutrófilos, atuando no endotélio, e por agir como um agente de limpeza extracelular do peróxido e transporte de cobre (SEGELMARK et al., 1997; CÉRON; ECKERSALL; MARTINEZ-SUBIELA, 2005).

Durante a gestação, o dano provocado no endométrio devido à implantação do embrião, aproximadamente 20 dias após a fecundação, é possível detectar níveis elevados de Cp. Devido a este fato, a Cp pode ser útil como teste gestacional na espécie canina (MARTIÍNEZ-SUBIELA; PARRA; CERÓN, 2004).

\section{Alfa 1 Glicoproteína ácida (APG)}

A alfa 1 glicoproteína, também conhecida como orosomucoide, é uma glicoproteína encontrada na região a-1 do eletroforetograma de proteínas. A APG possui um peso molecular de $43 \mathrm{kDa}$ e composta por $40,9 \%$ de carboidratos. É sintetizada e metabolizada principalmente pelo fígado (CÉRON; ECKERSALL; MARTINEZ-SUBIELA，2005; YUKI; ITOH; TAKASE, 2010). Existem evidências que a APG também possa ser produzida em locais extra-hepáticos, como os linfócitos. Foi demonstrado que os linfócitos produzem a APG, o que pode explicar o seu nível sérico elevado em cães e gatos com linfoma (CÉRON; ECKERSALL; MARTINEZ-SUBIELA, 2005; YUKI; ITOH; TAKASE, 2010). A produção extra-hepática da $A P G$ em humanos foi descrita nos rins, intestino, coração, e em diferentes tipos de leucócitos (FOURNIER et al., 2000). Adicionalmente, a APG pode-se originar na próstata e aparecer no fluído seminal (POLAND et al., 2002).

Acredita-se que a APG esteja envolvida com os mecanismos de defesa e suprime algumas funções imunes, como a fagocitose pelos neutrófilos, e a produção de linfócitos, através da modulação dos efeitos das interleucinas IL-1, IL-6 e o FNT (YUKI; ITOH; TAKASE, 2010).

Devido a sua baixa concentração em filhotes, a idade deve ser levada em consideração quando se faz o uso da APG como um marcador de doença (YUKI; ITOH; TAKASE, 2010).

A concentração sérica de APG pode ser um útil marcador de inflamação em cães e pode também ajudar a diferenciar casos agudos de crônicos (YUKI; ITOH; TAKASE, 2010). A APG é umas das proteínas de fase aguda que tem sua concentração aumentada durante a inflamação aguda, sendo uma PFA principal em gatos (ECKERSALL; BELL, 2010; YUKI; ITOH; TAKASE, 2010).

A mudança na glicosilação da APG foi descrita em gatos com peritonite infecciosa felina (PIF) (SHEAHAN et al., 2010), sendo, também, importante marcador em caso de linfoma felino (CÉRON; ECKERSALL; MARTINEZ-SUBIELA, 2005). Em casos de PIF, a quantificação de APG permitiu um avanço na precisão e determinação do diagnóstico, auxiliando na diferenciação em condições clínicas similares como nas miopatias (ECKERSALL, 2000).

Em cães, a concentração sérica da APG é um importante marcador de doenças inflamatórias e malignidade neoplásica, erliquiose e linfoma (MARTÍNEZ-SUBIELA et al., 2001; CÉRON; ECKERSALL; MARTINEZ-SUBIELA, 2005; YUKI; ITOH; TAKASE, 2010).

\section{Fibrinogênio}

É uma glicoproteína composta por duas subunidades formadas por três cadeias polipeptídicas ligadas entre si por pontes de dissulfeto. Sua concentração é constante no plasma sanguíneo de animais sadios, porém, durante a fase aguda de um processo inflamatório é liberada em maior quantidade pelos hepatócitos, de maneira que seus níveis aumentem consideravelmente (MARTÍNEZ-SUBIELA et al., 2001). O fibrinogênio também está envolvido na homeostase, fornecendo um substrato para formação de fibrina e na reparação tecidual (MURATA; SHIMADA; YOSHIOKA, 2004).

O padrão de produção e liberação do fibrinogênio é diferente nas diversas espécies animais e nos diferentes processos patológicos, podendo ter seus níveis aumentados em 1000 vezes durante uma inflamação (MARTÍNEZ-SUBIELA et al., 2001).

Cães com hiperadrenocorticismo (HAC) e outras doenças secundárias, apresentam um aumento nas concentrações de fibrinogênio, e diminuição nas concentrações de albumina (CALDIN et al., 2009). Durante a gestação ocorre aumento da concentração do fibrinogênio, sendo útil como teste gestacional na espécie canina (MARTIÍNEZ-SUBIELA; PARRA; CERÓN, 2004).

\section{Proteínas de fase aguda negativas}

\section{Albumina}

A albumina é considerada uma proteína de fase aguda negativa, diminuindo em casos de inflamação e/ou infecção. É a proteína mais abundante do sangue, constituindo 35 a $50 \%$ de proteína do plasma de cães e gatos sadios, sendo a maior banda observada no eletroforetograma (CÉRON; ECKERSALL; MARTINEZ-SUBIELA, 2005).

\section{Transferina}

A transferina também é considerada uma proteína de fase aguda negativa. É uma glicoproteína plasmática responsável pelo transporte do ferro na circulação. Em cães e gatos, a determinação das suas concentrações tem sido usada amplamente na avaliação do metabolismo do ferro e da homeostase (CÉRON; ECKERSALL; MARTINEZ-SUBIELA, 2005).

\section{Considerações Finais}

Existem três características que fazem da RFA uma ferramenta de aplicação prática na rotina da clínica em medicina veterinária: a RFA é um processo rápido que se desenvolve antes da estimulação de uma resposta do sistema imune específico, e em muitos casos antes mesmo do aparecimento dos sinais clínicos; a RFA se desenvolve quando ocorre injuria tecidual (infecção, neoplasia, trauma, etc), uma vez que se trata de uma resposta imune inespecífica; a produção e ação das PFA é espécie-específica (CÉRON; ECKERSALL; MARTINEZ-SUBIELA, 2005).

O estudo da cinética das PFA e das imunoglobulinas pode ser útil para a compreensão da fisiopatogenia dos vários processos inflamatórios e/ou infecciosos, contribuindo para 
o diagnóstico precoce e controle das enfermidades, avaliação da resposta vacinal, bem como para definição do prognóstico (GABAY; KUSHNER, 2001). A produção das PFA resulta de uma complexa interação entre inúmeros mediadores (incluindo as citocinas), receptores, moduladores e hormônios (GABAY; KUSHNER, 2001).

A concentração sérica das PFA na corrente sanguínea está relacionada com a severidade da desordem e com a extensão do tecido lesado, portanto, a quantificação da concentração das PFA pode fornecer informações importantes sobre o diagnóstico e prognóstico da doença (SERIN; ULUTAS, 2010; ALVES et al., 2010). Teoricamente, as PFA exibem uma resposta mais rápida do que as mudanças na contagem de leucócitos, especialmente em processos inflamatórios (CÉRON; ECKERSALL; MARTINEZ-SUBIELA, 2005).

Alguns cuidados devem ser tomados quando se faz o uso dos exames das PFA na monitoração do tratamento. Devido à sua baixa especificidade, diferentes condições e processos patológicos podem aumentar e manter elevados os níveis séricos das mesmas, impedindo a diminuição dessas proteínas em resposta a um determinado tratamento contra uma doença especifica (CÉRON; ECKERSALL; MARTINEZ-SUBIELA, 2005). Em algumas doenças, a concentração de determinadas PFA pode estar dentro do intervalo de referência, nesse caso a PFA não será útil no monitoramento de resposta ao tratamento. Nesses casos, ocorre uma diferença crítica entre os valores obtidos e a resposta individual de cada organismo (CÉRON; ECKERSALL; MARTINEZ-SUBIELA, 2005).

Não se encontra na literatura os níveis normais de valor de referência para cada uma das PFA para cães e gatos, pois, algumas PFA em determinadas não são possíveis de serem mensuradas em animais saudáveis, como a Hp em ruminantes (CÉRON; ECKERSALL; MARTINEZ-SUBIELA, 2005; SHEAHAN et al., 2010). Outra razão seria a variedade de métodos disponíveis para a determinação das diferentes proteínas pelos diferentes laboratórios. Dessa forma, recomenda-se que cada laboratório estabeleça seus próprios intervalos de referência para cada PFA a ser analisada.

Uma característica interessante das PFA é a possibilidade de detectar doenças subclínicas, prevendo futuras doenças clínicas que o animal possa vir apresentar (ECKERSALL; BELL, 2010). O uso das PFA ainda não é rotineiro na clínica de pequenos animais devido a uma série de limitações práticas, como a existência de poucos kits comerciais desenhados e validados para a espécie canina e felina; custo elevado de comercialização; escassez de estudos sobre a sensibilidade apresentada pelas PFA para o diagnóstico de vários processos patológicos; baixa especificidade para o diagnóstico etiológico (ECKERSALL; BELL, 2010).

$\mathrm{O}$ uso das PFA na rotina clínica em medicina veterinária está relacionado com a habilidade dessas proteínas em prognosticar a morbidade e mortalidade do paciente. A tecnologia poderá desenvolver meios para a caracterização de todas as proteínas do soro, pois, atualmente só um número limitado de proteínas séricas é usado para o diagnóstico de doenças. Espera-se que no futuro, as PFA sejam incluídas como um método de exame adicional nos perfis bioquímicos utilizados para avaliar a eficiência de tratamento, medicamentos e vacinas.

\section{Referências}

ALVES, A. E. et al. Leucogram and acute phase protein concentrations in queens submitted to conventional or videolaparoscopic ovariectomy. Arquivo Brasileiro de Medicina Veterinária e Zootecnia, Belo Horizonte, v. 62, n.1, p. 86-91, 2010.

CALDIN, M. et al. Serum acute phase protein concentration in dogs with hyperadrenocorticism with and without concurrent inflammatory conditions. Veterinary Clinical Pathology, Baton Rouge, v. 38, n. 1, p. 63-68, 2009.

CÉRON, J. J.; ECKERSALL, P. D.; MARTINEZSUBIELA, S. Acute phase proteins in dogs and cats: current knowledge and future perspectives. Veterinary Clinical Pathology, Baton Rouge, v. 34, n. 2, p. 85-99, 2005.

CROSSLEY, R. et al. Determinación de proteína C-reactiva em hembras caninas com tumores mamários benignos y malignos. Archivos Medicina Veterinária, Valdivia, v. 42, p. 101-105, 2010.

ECKERSALL, P. D.; BELL, R. Acute phase proteins: Biomarkers of infection and inflammation in veterinary medicine. The Veterinary Journal, London, v. 185, p. 23$27,2010$.

ECKERSALL, P. D. Recent advances and future prospects for the use of acute phase proteins as markers of disease in animals. Revue Médicine Vétérinaire, Toulouse, v. 151, n. 7, p. 577-584, 2000.

FOURNIER, T. et al. Alpha-1-acid glycoprotein. Biochemistry Biophysics Acta, Amsterdam, v. 1482, p. 157-171, 2000.

GABAY, C.; KUSHNER, I. Acute-phase proteins. Encyclopedia of life sciences. 2001, 171 p.

GARCIA, J. B. S.; ISSY, A. M.; SAKATA, R. K. Citocinas e anestesia. Revista Brasileira de Anestesiologia, Rio de Janeiro, v. 52, n.1, p. 86-100, 2002.

GRUYS, E. et al. Acute phase reaction and acute phase proteins. Journal Zhejiang University Scientific, Hangzhou, v. 11, p. 1045-1056, 2005.

KAJIKAWA, T. et al. Changes in concentrations of serum amyloid A protein, alpha 1-acid glycoprotein, haptoglobin, and $\mathrm{C}$-reactive protein in feline sera due to induced inflammation and surgery. Veterinary Immunology and Imunopathology, Amsterdam, v. 68, p. 91-98, 1999.

KANEKO, J. J.; HARVEY, J. W.; BRUSS, M. L. Clinical biochemistry of domestic animals. Academic Press, Burlington, v. 6, p. 117-155, 157-172, 2008.

KJELGAARD-HANSEN, M. Canine C-reactive protein: a study on the aplicabiliy of canine serum C-reactive protein. 2004. 130 f. Thesis (Veterinary Clinical Pathology) - 
Department of Small Animal Clinical Sciences, The Royal Veterinary and Agricultural University.

MARTÍNEZ-SUBIELA, S.; PARRA, N. D.; CERÓN, J. J. Principales aplicaciones de las proteínas de fase aguda em la clínica canina. Anales de Veterinaria da Murcia, Murcia, v. 20, p. 75-86, 2004.

MARTÍNEZ-SUBIELA, S. et al. Proteínas de fase aguda: conceptos básico y principales aplicaciones clínicas en medicina veterinária. Anales de Veterinaria da Murcia, Murcia, v. 17, p. 97-114, 2001

MORTENSEN, R. F.; ZHONG, W. Regulation of phagocytic leukocyte activities by $\mathrm{C}$-reative protein. Journal of Leukocyte Biology, New York, v. 67, p. 495$500,2000$.

MURATA, H.; SHIMADA, N.; YOSHIOKA, M. Current research on acute phase proteins in veterinary diagnosis: an overview. Veterinary Journal, London, v. 168, p. 28-40, 2004.

NAKAMURA, K. et al. Serum Levels of Interleukin-6, a1-Acid Glycoprotein, and Corticosterone in TwoWeek-Old Chickens Inoculated with Escherichia coli Lipopolysaccharide. Poultry Science, Oxford, v.77, p. 908911, 1998.

PETERSEN, H. H.; NIELSEN, J. P.; HEEGAARD, P. M. $H$. Application of acute phase protein measurements in veterinary clinical chemistry. Veterinary Research, Paris, v. 35 , p. $163-187,2004$

PLANELLAS, M. et al. Evaluation of serum haptoglobin and C-reactive protein in dogs with mammary tumors.

Veterinary Clinical Pathology, Baton Rouge, v. 38, n. 3, p. 348-352, 2009.

POLAND, D. C. W. et al. High levels of a1-acid glycoprotein in human seminal plasma is associated with high branching and expression of Lewis groups on its glycans: supporting evidence for a prostatic origin. Prostate, Malden, v. 52, p. 34-42, 2002.

RICE, E.W. Ceruloplasmin assay in serum: standardization of ceruloplasmin activity in terms of international enzyme units. Standard Methodology Clinical Chemistry, v. 4, p. 39-46, 1963.

SEGELMARK, M. et al. Binding and inhibition of myeloperoxidase (MPO): a major function of ceruloplasmin? Clinical and Experimental Immunology, Malden, v. 108, p.167-174, 1997.

SERIN, G.; ULUTAS, P. A. Measurement of serum acute phase proteins to monitor postoperative recovery in anoestrous bitches after ovariohysterectomy. Veterinary record, London, p. 20-22, 2010.

SHEAHAN, D. et al. Acute phase protein concentrations in dogs with nasal disease. Veterinary Record, London, v. 167, p. 895-899, 2010.

SHIM, B. S. et al. Studies on swine and canine serum haptoglobins. Biochimica et Biophysica Acta, v. 243, n.1, p.126-136, 1971.

YUKI, M.; ITOH, H.; TAKASE, K. Serum alpha-1-acid glycoprotein concentration in clinically healthy puppies and adult dogs and in dogs with various diseases. Veterinary Clinical Pathology, Baton Rouge, v. 39, p. 65-71, 2010.

Recebido em: 10/01/2014 Aceito em: 07/06/2014 